\title{
Changes in Thallus and Algal Cell Components of Two Lichen Species in Response to Low-Level Air Pollution at Pacific Northwest Forests
}

\author{
Hyung-Shim Y. Ra and Richard F. E. Crang
}

Department of Plant Biology, University of Illinois at Urbana-Champaign, 61801-3707

Lichens are known to be sensitive organisms to air pollution since they lack stomata and cuticles to prevent loading [1], but most experiments of air pollution effects on lichens have been conducted at very high concentrations of agents showing negative impacts [2]. Therefore, the information on lowlevel air pollution effects on lichen anatomy and ultrastructure is scant. For this research, Parmelia sulcata and Platismatia glauca, moderately resistant lichens to air pollution, were collected in winter from three field sites including a clean site (H.J. Andrews, OR) and two polluted sites (Bull Run, OR and Pack Forest, WA); all monitored by USDA/National Atmospheric Deposition Program. The primary objective of this study was to examine low-level air pollution effects on intrathalline and photobiont structure comparing with physiological results (from our previous observations).

Specimens from each site were prepared for both light and transmission electron microscopy, and micrographs quantified using morphometric overlay grids or analytical software (AIS).

The thalli of both species from polluted sites had more soredia and possessed a darker green color. The algal cell proportion in the thallus of each species was slightly higher in polluted samples than in clean samples. The photobiont of $P$. sulcata at H.J. Andrews seen with TEM had a more undulate chloroplast envelope and wavier thylakoid membranes than that found in specimens from Pack Forest (Fig. 1). In structural quantification, both cytoplasmic lipid content and algal cell wall thickness were higher in P. glauca at Bull Run than at H.J. Andrews, while the amount of lipid was higher at Pack Forest in P. sulcata than at H.J. Andrews. However, the pyrenoglobuli portion in pyrenoids of both species was much higher at H.J. Andrews than at either Bull Run or Pack Forest (Fig. 2).

In regard to physiological data, net carbon uptake was slightly higher in both species at polluted sites, while total chlorophyll content was significantly higher in both polluted species. Our results were similar to a field experiment showing that cell wall and cytoplasmic lipids of two Bryoria species positively correlated with distance from a smelter site [3], although round and stretched chloroplast envelopes were found as a damaged sign following sulfur dioxide fumigation [4]. These results indicate that with low level of air pollution, these two lichens can benefit by reserving more storage in algal cell walls as well as lipid in cytoplasm while they reserve less lipid in pyrenoglobuli of pyrenoids.

\section{References:}

[1] Gries C. (1996) Lichens as indicators of air pollution. In: Nash III T. H., Ed., Lichen Biology, pp. 240-254. Cambridge University Press.

[2] Eversman S. and Sigal L. L. (1987) Effects of $\mathrm{SO}_{2}, \mathrm{O}_{3}$, and $\mathrm{SO}_{2}$ and $\mathrm{O}_{3}$ in combination on photosynthesis and ultrastructure of two lichen species. Can. J. Bot. 65:1806-1818.

[3] Tarhanen S. et al. (2000) Severe photobiont injuries of lichens are strongly associated with air pollution. New Phytologist 147:579-590.

[4] Holopainen T. and Karenlampi L. (1984) Injuries to lichen ultrastructure caused by sulphur dioxide fumigations. New Phytol. 98:285-294. 

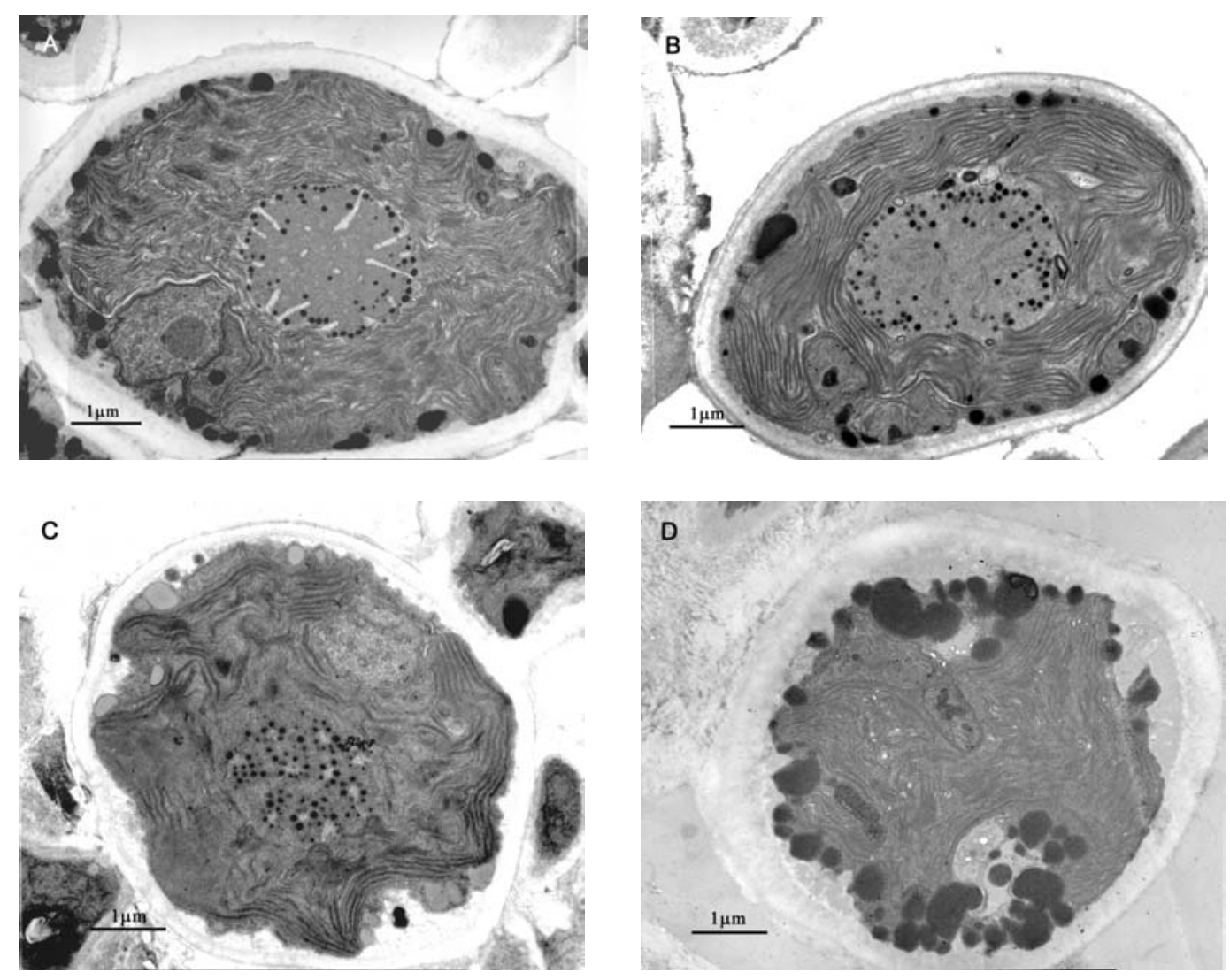

Figure 1. Photobiont (Trebouxia sp.) ultrastructural changes of P. sulcata (A and B) and P. glauca (C and D). P. sulcata at H.J. Andrews (A) had more undulate chloroplasts, wavier thylakoid membranes, and pyrenoglobuli organized toward the edge of pyrenoids as compared to the ones at Pack Forest (B). P. glauca showed higher amount of lipids in cytoplasm at Bull Run (D) than at H.J. Andrews (C).
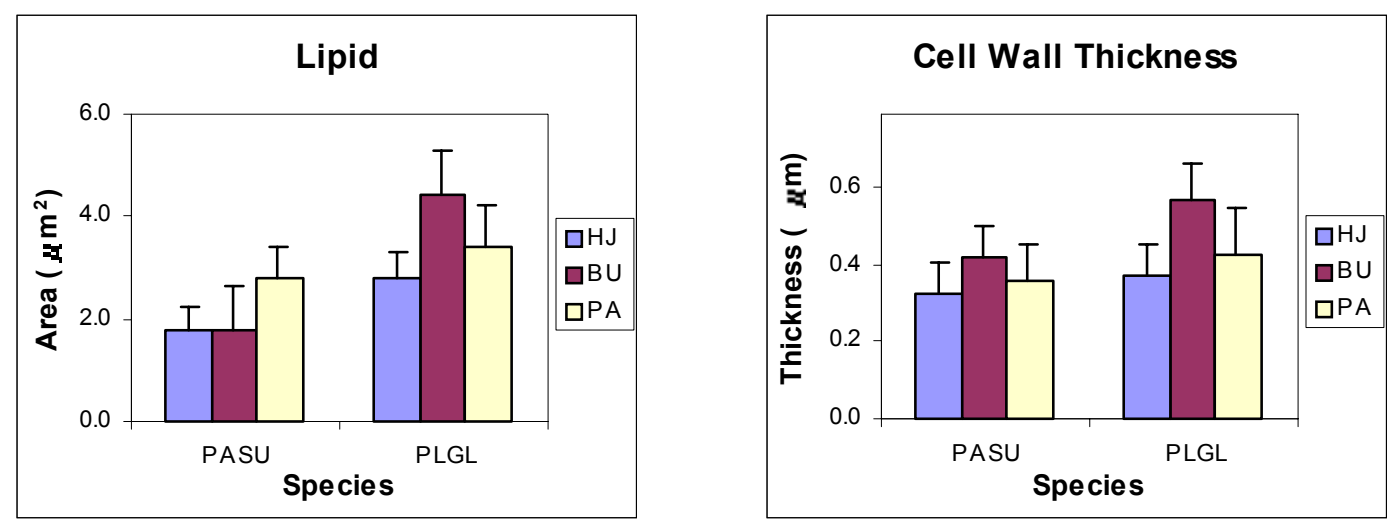

Figure 2. Cell wall thickness and lipid area of $P$. sulcata and $P$. glauca were increased at polluted sites. Lipid content was greater in specimens from Pack Forest than at H.J. Andrews in P. sulcata. Both cell wall thickness and lipid content were higher at Bull Run than at H.J. Andrews in P. glauca. 